\title{
How do students become self-directed learners in the EFL flipped-class pedagogy? A study in higher education
}

\author{
Zamzami Zainuddin $^{1 *}$, Habiburrahim ${ }^{2}$, Safrul Muluk ${ }^{3}$, and Cut Muftia Keumala ${ }^{4}$ \\ ${ }^{1}$ Information and Technology Studies, Faculty of Education, The University of Hong Kong, \\ Pokfulam Road, Hong Kong \\ ${ }^{2,3}$ English Education Department, Universitas Islam Negeri Ar-Raniry, Banda Aceh, Indonesia \\ ${ }^{4}$ Sekolah Tinggi Ilmu Administrasi (STIA) Nasional, Lhokseumawe, Indonesia
}

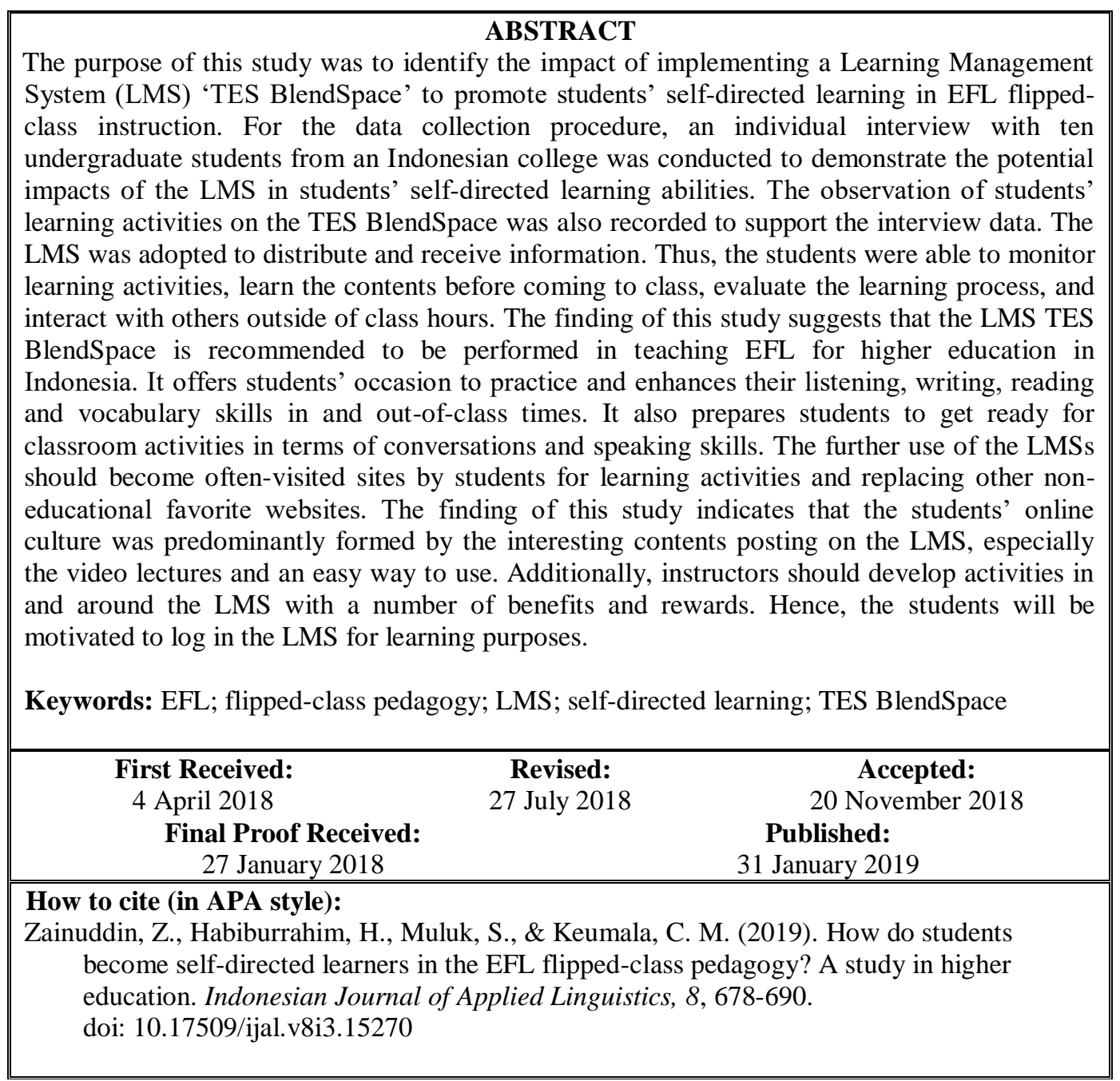

\section{INTRODUCTION}

Technological growth occurs in every single minute, and it demands the instructors to upgrade their teaching practices through innovative instructions (Walder, 2015). Today's learners grow up immersed as digital natives and familiar with a wide range of digital devices. They also may have different learning styles, motivation, and engagement approach to the learning process (Hwang, Chiu, \& Chen, 2015). Therefore, these actualities need contemporary pedagogical models and trends in order to accomplish students' 21st-century skills, needs, and preferences. The flipped-class pedagogy is one of those variants implemented in current teaching and learning practices by adopting technological tools such as video lectures and LMS.

\footnotetext{
* Corresponding Author

Email: zamzamizain@hku.hk
} 
The flipped-class is often defined as an instructional strategy, a part of blended learning instruction, where the students understand and comprehend the instructional contents before attending class by watching video-recorded lectures (Chuang, Weng, \& Chen, 2018). In-class activities are subsequently more focused on promoting students' higher-order thinking skills or knowledge construction, such as small group discussion, dialog, presentation, and take-and-give conversation or the so-called Socratic questioning process (Slomanson, 2014). Simply put, the flipped-class pedagogy facilitates content retrieval autonomously before attending class, enables peer communication and facilitates an asynchronous channel for watching video lectures while replacing repetitive conventional classroom lectures. The flipped classroom is also defined as synonymous with using the videos and replacing the conventional classroom lectures. In order to preserve the time designing or recording the video lessons, the lecturers may use an alternative way by adopting a short video lecture from several free websites such as Khan Academy, TED-Ed, BBC News, or YouTube $(\mathrm{Ng}, 2015)$.

This innovative pedagogy has gained prominence in higher education institutions as an alternative pedagogical model reversing what traditionally occurs in and out of the class activities. As a newly emerged teaching methodology, it has the potential to address the constraints of EFL contexts, allowing more time for students to use English inside and outside the classroom because of the inverted learning process (Lee \& Wallace, 2018). Lectures are removed, and the removed content is often delivered to students through pre-class input materials like video recordings. However, flipped materials do not always have to be tied to technology (Lockwood \& Folse, 2014). Students can study various types of materials (e.g., readings from a textbook and worksheet developed by their teachers) on their own outside of class time and grasp the meaning of the content.

The fact that most students today are familiar with different technological tools and most of them allocate most of their daily hours using some sorts of technological devices would be a contributing factor in the effort to improve English language teaching (Lai, 2015). In the context of EFL flipped-class pedagogy, there are numerous reasons that this pedagogy has successfully promoted students' positive learning outcomes and self-directed learning skills. For instance, Chuang et al. (2018) reported that pre-content courses (the online video course) outside of the class and quiz strategy before in-class have successfully enhanced students' learning motivation and self-paced learning skills in the Applied English for Vocational Education course. Besides, Lin and Hwang (2018) also conducted a study aiming at improving EFL students' English oral presentation in the flipped classroom in a Taiwanese university. An 18-week research design was implemented in the online community-based flipped classroom using Facebook as the platform for facilitating and recording peer-to-peer interactions during the flipped learning process. The experimental results reveal positive effects of the online communitybased flipped instruction over the conventional videobased instruction. Moreover, all participants in the English Language Teaching program reveal a positive attitude toward independent learning activities outside of the class through pre-class video lectures; the students might be able to review the lessons at anytime they wanted and being able to decide on their own pacing (Kurt, 2017).

Although many instructors and researchers have recently implemented and published the positive effects of the flipped-class pedagogy, there is little empirical evidence about whether this approach can actually promote students' positive learning outcomes and selfdirected learning skills in foreign language studies, particularly in the Indonesian higher education context. Thus, in order to fill this gap, this study aims to examine how the flipped-class pedagogy impact students' self-efficacy skills in the EFL classroom. This study is expected to transform the EFL classroom from being a traditional to a technology-based pedagogical approach, particularly in the developing countries. In order to make it more simple and to save time and budget, the instructor in this study adopted pre-class video lessons from YouTube channel with a short duration and attractive contents. As suggested by Bergmann and Sams (2012) that in designing or selecting the video lesson, the content of a video should be attractive and its duration is not too long. Other researchers also suggested that the video lesson should be designed attractively in order to make students comfortable and interested in watching. Short and informal videos will also make students becoming more engaging (Kim, Kim, Khera, \& Getman, 2014). The researchers, therefore, in this work applied attractive video lessons adopted from YouTube and posted on the LMS TES BlendSpace (https://www.tes.com/lessons) with the aim of enhancing students' self-directed learning skills, particularly outside of the class time.

\section{Self-directed learning skills}

Based on its history, self-directed learning skill started in the early 20 th century with a focus on adult education and later was developed as a skill for children to learn the contents independently based on the intrinsic motivation (Garrison, 1997). Through self-directed learning skill, children would be able to collaborate with peers and solve the problem independently with limited or no guidance from the instructor. Knowles (1989) defined self-directed learning as " $a$ process in which individuals take the initiative, with or without the help from others, in diagnosing their learning needs, formulating goals, identifying human and material resources, choosing and implementing appropriate learning strategies and evaluating learning outcomes" (p. 18). While Garrison (1997) noticed that self-directed learner is an autonomous learners' skill in solving the problem through intrinsic motivation. In teaching 
English, Benson (2009) mentioned that self-directed learning skill becomes a fundamental goal for students to successfully achieve their learning outcomes. Selfdirected learning skill in teaching English enables students to practice the language skill autonomously everywhere and anytime whether in the classroom or outside of class hours. Long (1989) further introduced psychological dimension to self-directed learning, asserting that self-directed learning involves a process of self-generating activities to accomplish educational goals and that this process not only is predicted by the psychological situations of the learner but also contributes to the further development of psychological situations.

Although diverse interpretations of self-directed learning have been widely discussed in various studies, Brookfield (2009) designated that all researchers might agree that the common point of this definition is the learners' responsibility for their own learning. With guidance from the instructor, the learners are able to determine what and how they will learn, as well as evaluate their own learning progress. Nowadays, there has been a considerable increase in the use of ICT in education. Due to the readily available ICT enabled tools in almost every educational institutions, selfdirected learning can be enhanced. The context of selfdirected learning has now changed with online learning, greater access to technology, personalized learning experiences, and access to information sources that were not available earlier. Schools and universities are recognizing the significance of self-directed learning and are encouraging their instructors to facilitate such type of learning either in the classrooms or outside of the classroom. Students' opinions on Self-directed Learning have indicated that social media including LMS and online video contents should be extensively employed to enhance self-direct learning skills among students and between students and instructor (Dabbagh \& Kitsantas, 2013).

In line with this, the flipped classroom model has become one of the latest learning methods in recent years, and it requires the utilization of technological devices to support students' learning particularly outside of the class. This method provides a great opportunity for students to learn course concepts outside the classroom environment with online educational materials such as video, film, and voice, so that classroom time is used for active learning such as problem-solving and practical applications (Bergmann $\&$ Sams, 2012). The flipped classroom has highlighted the value of self-directed learning in schools and has consequently led to changes in the role of the traditional classroom teacher. Numerous studies have also reported that self-regulated learning skills are aligned with EFL flipped-class instruction (e.g., Kurt, 2017; Lai, Hsiao, \& Hsieh 2018; Lin \& Hwang, 2018). For instance, Lin and Hwang (2018) reported that flipped-class instruction helps learners become more responsible and autonomous in their learning and communication. It also shows a significantly higher frequency of students' online participation outside of the class.

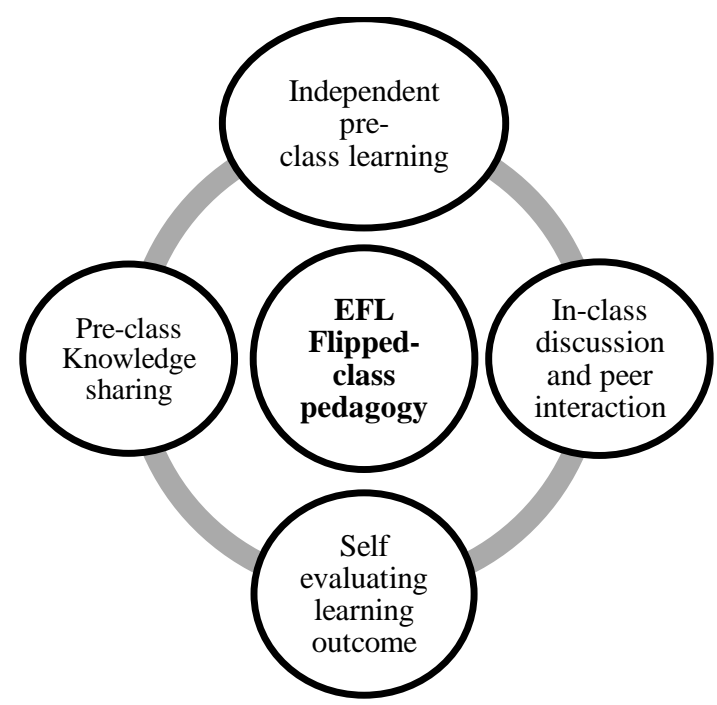

Figure 1. A conceptual framework of self-directed learning in the EFL flipped-class pedagogy

Based on the discussion above, a conceptual framework of self-directed learning for EFL flippedclass instruction is proposed below (See Figure 1). This framework is intended to give a holistic view of the process of the study, particularly in collecting, analyzing, describing, and interpreting the data. As summarized in the framework, four main activities were expected to be achieved by the learners in the EFL flipped class activities. Firstly, it is an independent preclass learning activity, where the learners were required to review one of the video-recorded lectures before attending class. Secondly, knowledge distribution or information sharing with peers were conducted online outside of the class via the LMS. Thirdly, face-to-face discussion or peer-interaction in the class is where the learners were expected to be able to communicate, 
reflect, ask, and discuss the issue that they had learned before attending class. Fourthly, self- and peerevaluation required the learners to be able to evaluate their own and peer's work and learning progress at the end of the class.

\section{LMS TES BlendSpace}

Unlike Blog which is designed and used for various purposes, TES BlendSpace is an LMS designed for educational purposes. It focuses on flipped classroom and project-based learning. A teacher or instructor can create free classroom and share various contents for students' learning outside the class. The following Figure 2 shows the home page of TES BlendSpace where a teacher and student can register as users.

To begin creating the class and lesson, the teacher/ instructor should register as a user at the homepage (https://www.TES.com). By clicking "JOIN FREE," the user will be guided to two options whether teacher or students' users. As a teacher, she/ he must register and click "I'm a TEACHER." Then, the user can fill the form including name, e-mail, and password. The user can continue creating the class, choose a grade level and the name of the class. After creating the class and obtaining the class code, the user may create new lessons by clicking "Lessons" or "New Lesson." Then, the user will be directed to a page which has six columns where the content will be put or uploaded. In the column, the teacher can upload the texts, quizzes or video. The teacher can also write the instruction on the column informing what students should do with the video and what activities they should prepare for the next class meeting. The content of learning can be dragged to the column, or it can be searched by clicking on the top right corner. There are numerous searches provided such as YouTube search, Google, Flickr search, Educreations Search, Search Gooru, Insert from Dropbox and Insert from Drive. The following figures 3 shows the space of uploading content of learning and the contents from several sources.

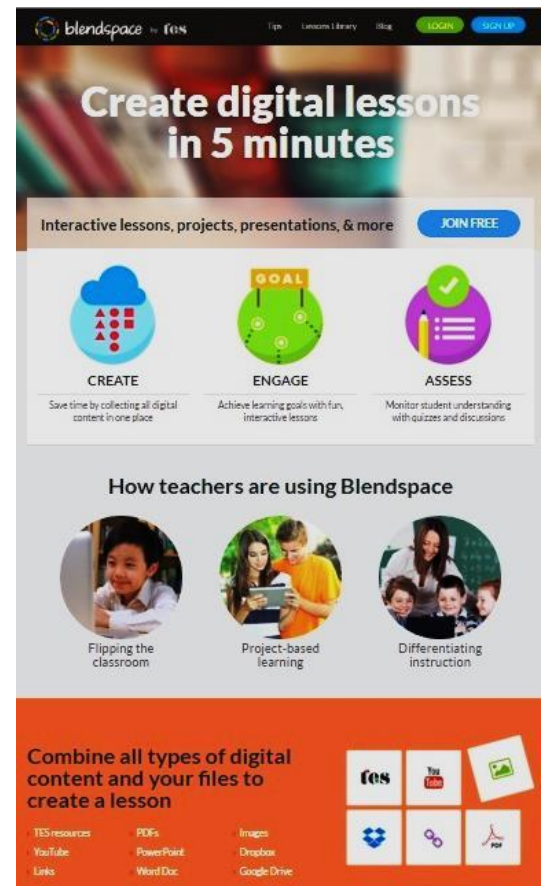

Figure 2. The homepage of TES BlendSpace

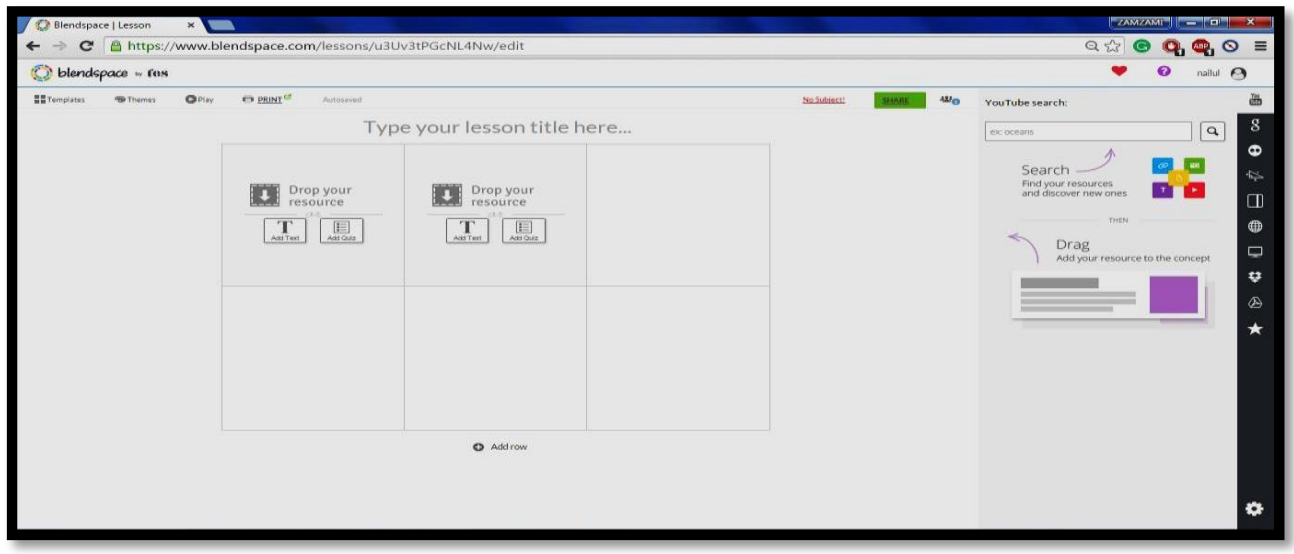

Figure 3. Columns of uploading contents of the learning 


\section{METHOD}

\section{Research design}

This study was administered to review the impacts of employing the LMS TES BlendSpace to foster students' self-directed learning capacity in the EFL Flipped-class pedagogical instruction. It particularly observed the interactions and engagement between the students and a free web 2.0 LMS TES BlendSpace in teaching-learning EFL. Although the intervention was given to students within a period of two months, the results of this research were not collected through a quantitative experiment or test with a rationale to acquire more indepth information through a qualitative lens. At the end of the intervention, the data were gathered from the qualitative interviews and online observations of students' activities on the LMS TES BlendSpace. Semistructured interview questions were given to respondents, which were then transcribed as recommended by Creswell (2012). Therefore, in terms of research design, this work can be considered as a case study since it examined the impact of a small flippedclass size using a small group instruction. A particular case examined in this work was students' learning experiences in the EFL flipped-class instruction in terms of self-directed learning skills. In line with this, Creswell (2012) mentioned that case study research is a qualitative approach, in which the researcher explores a bounded system (a case), an event or a small group of community members with an in-depth analysis.

\section{Participants}

Ten students from an EFL flipped-class intervention group at a university in Indonesia were selected as samples of this case study. In order to avoid gender bias in selecting the samples, quota sampling as a nonprobability sampling technique was employed to decide the portion of female and male interviewees. At least 5 females and 5 males were invited and volunteered themselves to be interviewed, and their ages span between 19 and 20 years old. More in-depth information was expected to gain from these participants as they had worked and experienced learning in the flipped-class pedagogy and the use of the LMS TES BlendSpace within a period of two months. In order to keep students' privacy, all ten students in the interview were reported anonymously or arranged alphabetically. The interviews ranged in length from 15-20 minutes and questions were recorded verbatim.

\section{Course design and flipped-class intervention}

In this EFL flipped-class research, the instructor conducted a face-to-face meeting in the classroom once a week with a duration of 1 hour and 40 minutes (100 minutes). Six steps had been implemented by the instructor in flipping the English language course. First, the instructor shared one video every week on a TES BlendSpace. The video was adopted from a YouTube channel. Overall, six videos had been shared by the instructor in one semester. The duration of videos varied; the shortest video was 4:52 minutes and the longest one was 8:15 minutes. Besides, the instructor also shared other supporting materials such as PDF articles and websites. The following Figure 4 shows several YouTube videos posted on the TES BlendSpace.

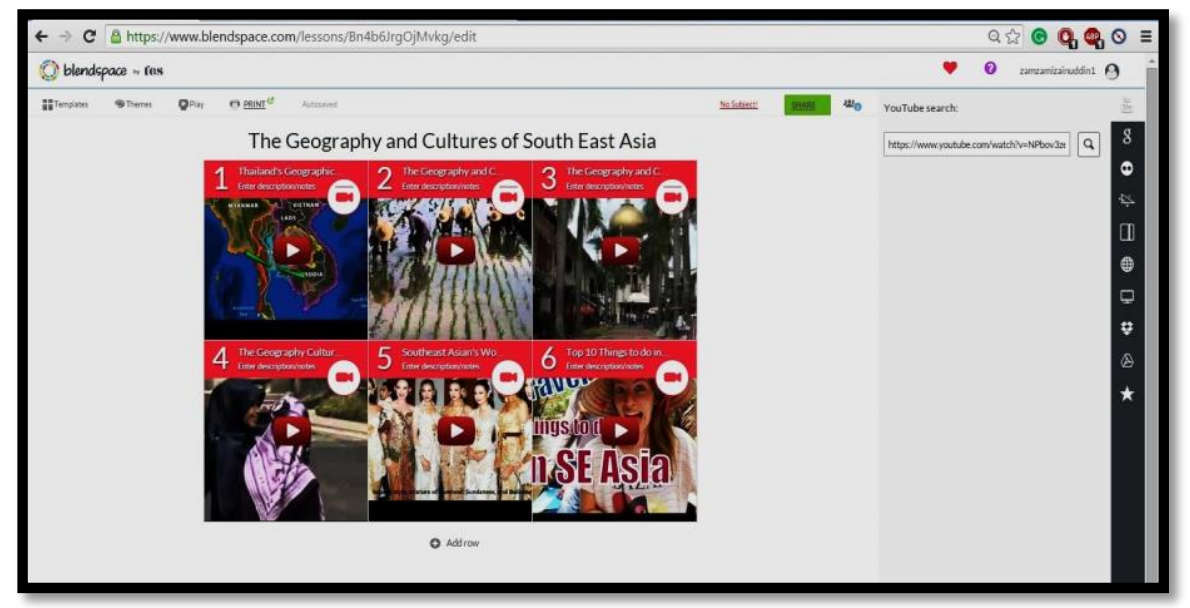

Figure 4. The contents of YouTube have been uploaded on the TES BlendSpace

Second, students watched a video and read other supporting materials before coming to class. Third, students conducted an online discussion by posting questions and comments regarding the video contents. The use of TES BlendSpace is especially relevant for enhancing students' collaboration since it has a special space for collaborative tasks among students as well as with the instructor. It provides a synchronous chat and asynchronous discussion board. The students in this study were able to post their comments and asked questions to the group online. Fourth, when in-class, a 40-minute session was allocated for a listening exercise. Fifth, a 45-minute session was allocated for conversation activity, and sixth, a 15-minute session was allocated for interactive feedback and a small quiz session. Feedbacks were given by the instructor or students (peer-evaluation). The following Figure 5 summarizes six steps of instruction in flipping the English language course. 


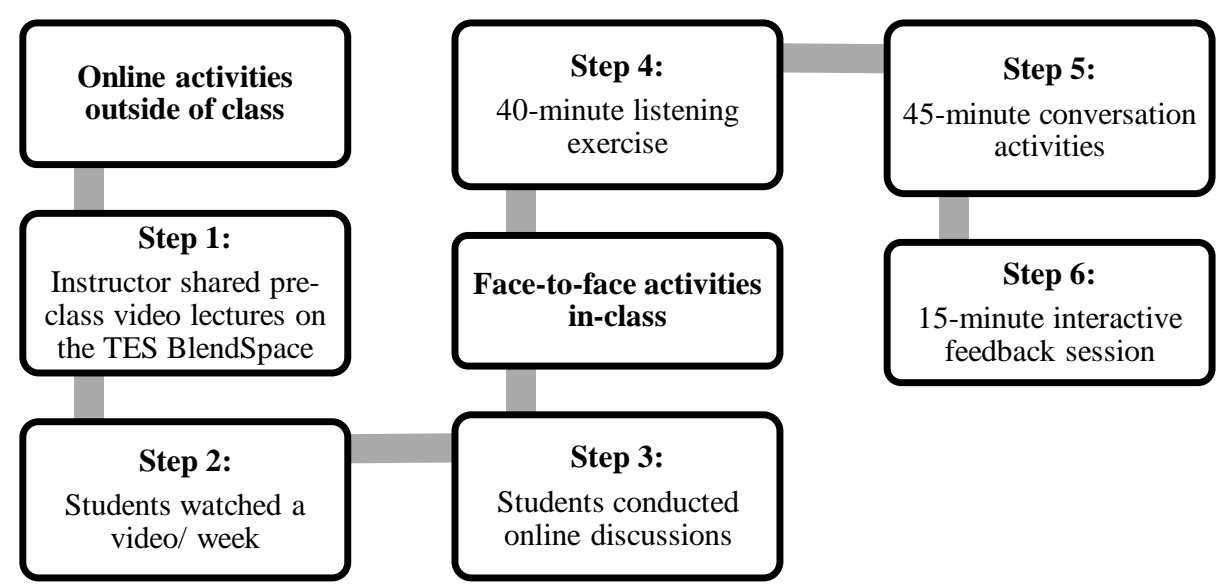

Figure 5. Students' activities in the EFL flipped-class instruction

\section{Data collection and analysis}

The data were collected through a semi-structured interview at the end of the intervention to gain in-depth information with regard to students' learning experiences in the EFL flipped-class pedagogical instruction. The interviews were conducted with duration ranged from 15-20 minutes for each interviewee. The data were analyzed using thematic analysis procedures to generate a list of possible themes based on the purpose of the study. The information was firstly recorded on audiotapes, with the participants' agreement, and was later transcribed by the researchers to discover any themes. The interview analysis was conducted via a computer-assisted qualitative data analysis software program (i.e., NVivo 12). For the online observation analysis, students' activities on the LMS were observed, recorded, and presented descriptively in the form of print screens.

\section{FINDINGS}

The findings of this study revealed that almost all students stated that the use of LMS TES BlendSpace had positive influences in learning EFL. Several positive themes emerged during personal interviews as follows:

\section{Receiving and distributing information}

Most students acknowledged the information distribution as the primary function of the LMS TES BlendSpace. One student expressed the BlendSapce as a beneficial medium to share and acquire new information. Another student mentioned that this LMS was useful in making information available immediately and in saving energy and money. By using this LMS, class materials could be shared online and students could access them conveniently. At the same time, the instructors may save their times in preparing printing materials or a hard copy for students' in-class activities. The type of information distribution in this study could be in a form of an announcement, learning materials, or homework. Students or instructors were able to post announcements to the LMS group, distributed some learning materials for group sharing, and established a discussion forum. The following section contains students' statements in relation to the use of TES BlendSpace website and its benefits in terms of information distribution. See the example of announcement distribution in Figure 6.

"TES BlendSpace allows me to know new announcement from my lecturer, the lecturer shares announcement by a single posting and everyone can assess it immediately, she [lecturer] doesn't need to call or text students one-by-one for the announcement." (Student C)

"I can access this site every day to update new information from my lecturer or classmates. This site also allows me to check upcoming events, and share papers and videos to others with a single posting." (Student H)

"I use the TES BlendSpace primarily as a source of information for my learning activities and I can exchange information with my friends through this web. Also, important information or problem can be directly shared and received here." (Student F)

Features provided on the TES BlendSpace allow students to manage a discussion forum, collect and share resources, receive and share an announcement, upload the video lessons, add the assignment, and create flipped lessons. This site enables instructors to design lesson plans easily, the site also provides a diversity of resources such as YouTube Videos, Google Search Results, Google Images, and Flicker images. For those who could not attend the class, they can contact the instructor immediately on the LMS TES BlendSpace. The instructor could also inform students whether he/she would come to class on time or not, or whether the class was rescheduled.

\section{Monitoring learning activities outside of class}

The LMS TES BlendSpace element is designed to promote students' to monitor their learning activities, especially during outside of-class-hours. Six interviewees acknowledged that they accessed the LMS regularly before attending the class to check update 
information about the topic discussion from peers and instructor.

"I $\log$ in into the LMS to check if there is new information or posting there. Yeah... I see other comments, questions, and new materials, this makes me $\log$ in the TES BlendSpace more often. This site made me able to control the progress of my learning activities outside the class, and I could prepare for the next class activities of course."
This statement was strengthened by student $\mathrm{F}$, she declared:

"I always access this Web to check any update information such as new videos or students' comments. I received many replies on my questions and comments. Therefore, I often access them every day, and I was able to read new information, respond comments, and ask questions to my friends and instructor. Through this website, I would never miss any single update information."

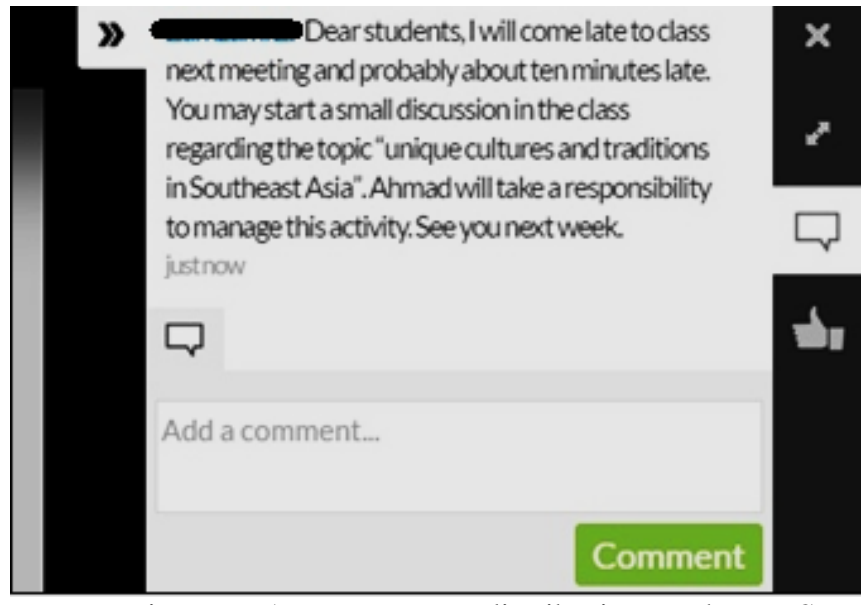

Figure 6. Announcement distribution on the LMS

Two students mentioned that by monitoring information on the LMS, they did not need to ask friends about new information related to the next class meeting, student A stated:

"I can update the information independently at any time, in the previous class, I always contact my friends to ask about any assignment or update information about the next class meeting, but I don't need in this class, all learning information is updated."

Student $G$ also declared that the use of LMS Test BlenSpace was very helpful to control new information independently outside of class hours:

"Although we are not in the class, we can still follow any update information about learning activities online outside the class."

Some also described that the TES BlendSpace has a good design and is easy to use. For example, one student described the TES BlendSpace enabled students to access the course material when they missed the class:

"When I miss the class, I would not miss the lesson because I could access it on the LMS conveniently from my home, all materials are posted on the Test BlendSpace and I could learn it by myself.............and I think this site is simple to use and the content of the video is also interesting, everyone can access it easily, yes, great."

However, only two students admitted that they rarely $\log$ in to the LMS because they did not find any interesting topic posted by the instructor and there were many questions posted by students. In this case, student J acknowledged:

"If there is any interesting topic to me, I will often $\log$ in and check the TES BlendSpace, if not, I am very lazy to access it".

This declaration was strengthened by student I:

".......if the video and topic discussion is interesting to me, I will often study more about it and posted questions actively and respond to comments."

These two statements indicated that the attractiveness and interesting of video lectures or materials on the TES BlendSpace played a very significant role in establishing students' motivation and engagement to monitor the LMS regularly.

\section{Students' pre-class learning content}

The flipped classroom approach has significantly enhanced students' autonomous learning skill by mastering the content at home before attending class, so they were prepared for classroom activities. By watching a video lesson and reading printed materials, students became more confident in-class activities. Students acknowledged that the use of LMS TESBlendSpace helped them access the content anytime and wherever. Students also explained that by mastering the content before attending the class allowed them to come up with critical thinking or immediate critical questions during the class discussion. For example, student $\mathrm{E}$ in the interview reported: 
"I can prepare the subject outside the class by watching the video lesson posted on the LMS TES BlendSpace, and this activity makes me more confident for classroom activities and discussions."

\begin{abstract}
"By watching a YouTube video outside the class, I could prepare what would be discussed and asked in the classroom. I also could watch the video according to my preferred time, before sleeping on my bed or when waking up in the morning.......also, I could repeat watching the video several times when I did not understand." (Student C)

"Yes, by watching the video outside the class, I can watch it on my own ways and when I don't understand, I can post a question and discuss with friends on the TES BlendSpace. These activities make me ready and confident to participate in class discussion." (Student G)
\end{abstract}

By providing lectures online, students have opportunities to learn and understand the content at their own pace. Once they did not understand the materials they learned, they could re-read and explored the materials according to their needs. By providing the content on the LMS before the actual class hours, some students who needed more times to master the content would not be left behind. On the other hand, for those who had understood the materials, they could move on with other materials. This means that students might not learn the same contents at the same time outside the class hours.

Two students also reported that accessing the LMS became their learning habit every night before going to bed and they did not realize that they spent every night accessing the LMS online course like other social media such as Facebook and Twitter. In this case, the LMS TES BlendSpace has successfully contributed to help blend students' learning activities between face-to-face meeting in the class and online learning outside the class. They also asserted that watching a video lesson outside the class gave them ample opportunities to practice English listening and writing skill, as well as note-taking. For example, student A and D stated:

"All video lessons posted by the instructor were in
English, and I could practice my English listening skill
by watching those videos on the LMS". "I was able to practice English writing by taking a note about the video I watched, and posted a question and comment on the LMS".

\section{Students' peer interaction}

The flipped learning environment allocates more times for the students to interact with peers and instructor both in and out of class hours. This finding proved that flipped classrooms established strong social interactions among students. It helped students to teach and exchange knowledge with each other. Flipped classrooms also helped low ability students to learn and ask questions to their peers. In particular, all students in the interviews recognized that the use of LMS TES BlendSpace in the flipped learning class contributed to their active interactions with other students outside the class hours (See Figure 7). Student B verbalized a positive response and demonstrated:

"In this class, we could establish a good interaction with peers, not only in-class discussion but also outof-class times.......we have a chance to talk and discuss with our friends through a chat forum on the TES BlendSpace".

\section{Student F also supported:}

\begin{abstract}
"In other class, I rarely communicate with my friends outside of classroom; we only have a discussion with face-to-face in the class. It is very difficult if I want to contact my friends asking the lesson or homework".
\end{abstract}

Nonetheless, two students claimed that they did not talk much in class or confidently expressed ideas verbally during the class discussion. But through the LMS, they felt confident to express ideas by posting statements or giving comments online. The LMS TES BlendSpace was also described to facilitate students to know each other more personally. This showed that the LMS was recognized as a virtual environment for interacting, communicating, and understanding students' character. For example, student D and E reported:

“Through students' comments and postings on the LMS, I was able to know their characters such as their critical thinking, respectable, or helpful students."

\begin{abstract}
"The TES BlendSpace is a good application for online interaction outside the class. Through this web, I could communicate with my classmates every day after class times. I also could know them personally especially their character by reading their comments and questions on the website."
\end{abstract}

This flipped learning provided 45-minute conversation activities in the class. Therefore, some students acknowledged that the class activities were very valuable for student-centered activities such as practicing English conversation and dialogue in a small group. Respondent A noted how the flipped classroom provided a valuable time to interact with other students in practicing English writing outside the class and speaking skill in the class discussion.

\begin{abstract}
"The online Web TES BlendSpace is very helpful for us, we can practice our English outside the class with peers, and we can practice listening to the native speakers on the video, practice writing, and reading, as well as understanding new vocabularies."
\end{abstract}

In a similar vein, students D also acknowledged the same perceptions.

"...using the online Web application outside the class enabled me to practice English with my friends and 
improved my practice in English listening, reading and writing .... When outside the class, I could practice my writing skill by posting a comment and ask a question in English, reading some English texts, mmmm...also I could practice my English conversation confidently in a group discussion."

The resources or links posted by a student in a discussion forum also enabled students to receive new information and establish a new discussion topic. Two students agreed that new resources shared by other students on the LMS opened their minds toward other relevant issues. For example, student A acknowledged:
"My friends' postings really help me improve my understanding toward the subject. Sometimes the video lessons were unclear, and I got further deep information from other sources posted by my friends." (See Figure 7)

This was further illustrated by student H's comments:

"My instructor posted a YouTube video about a South East Asian's women national dress, and I could not understand in-detailed about the video, then my friends share other links and help me understand this topic comprehensively."

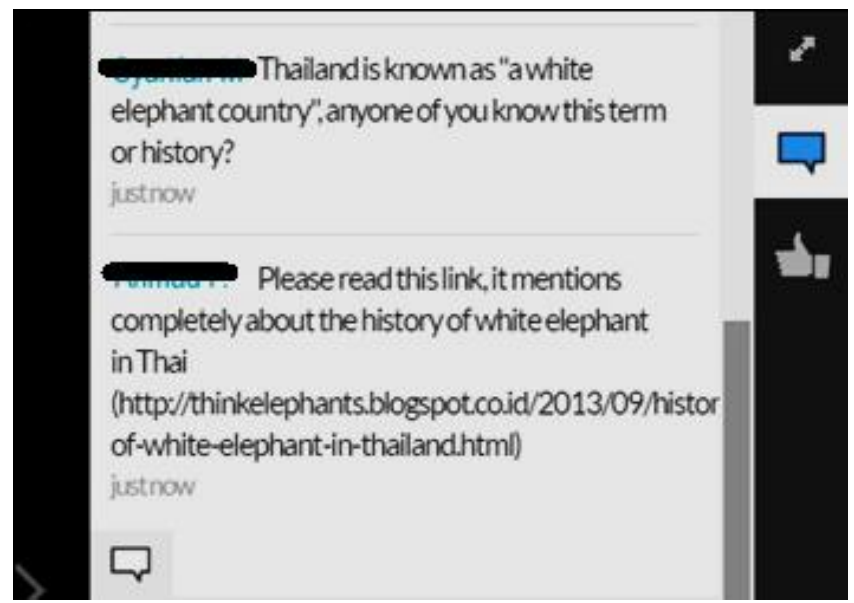

Figure 7. Student-peer interaction on the LMS

Furthermore, students-students' interaction had also constructed students' eagerness to ask questions to their peers, as mentioned by student $\mathrm{H}$ :

"I can post a question regarding the unclear video or topic. My friends will respond to my question immediately."

The flipped learning class with the use of TES BlendSpace has also increased the interaction between students and instructor. The interaction was not only established in the class activities but also outside the class hours. The instructor was able to interact with each student more personally or more one-on-one interaction with students. This enabled the instructor to give immediate feedback in order to improve the student's progress. Also, in the classroom, the instructor no longer stood in front of the class, but she participated and involved in students' discussion. Students expressed their comfort and amusement of having times interacting with the instructor during the class hours and after the class through online TES BlendSpace. Student $\mathrm{J}$ mentioned:

"The instructor was available outside of class time, the online activities on the TES BlendSpace made me easier to communicate with the lecturer outside the class."
The statement was best expressed by Student $\mathrm{C}$ who compared her experience interacting with an instructor in a flipped classroom and traditional classroom, she stated:

"This class makes me easy to talk to the lecturer in the class, and it was very different with my previous class where I only sit, listen passively to my lecturer's talk and students only stay silently. The communication with the lecturer is only limited in the class, but here we can continue the discussion online on the LSM outside the class."

\section{Students self-evaluating learning skills}

All interviewees acknowledged that the flipped class projects provided them chances to assess their performance as well as their colleagues'. It also enabled them to know their colleagues' level in understanding the subject. Student B and I stated that they regularly reviewed if their peers made any mistakes in their postings on the LMS. Through peer-evaluation, students could correct the mistakes made by their peers as well as their own mistakes. Through self-evaluation, students also declared that they could identify their weaknesses in comparison with others.

“After looking at other students' comments and performance both in and out of class, I understand the level of my ability. I realize how competence I am in the class." 
Student A always compared her postings with other students' posting and tried to correct some mistakes especially in the grammatical errors (see Figure 8). Whereas student $\mathrm{E}$ mentioned that she never tried to compare her posting with others. She only attempted to learn from other students' writing styles and word choice usages. Student B reported:

"I could evaluate my writing ability through my friends' comment. For example, I made a mistake in grammar and my friends would correct it immediately."

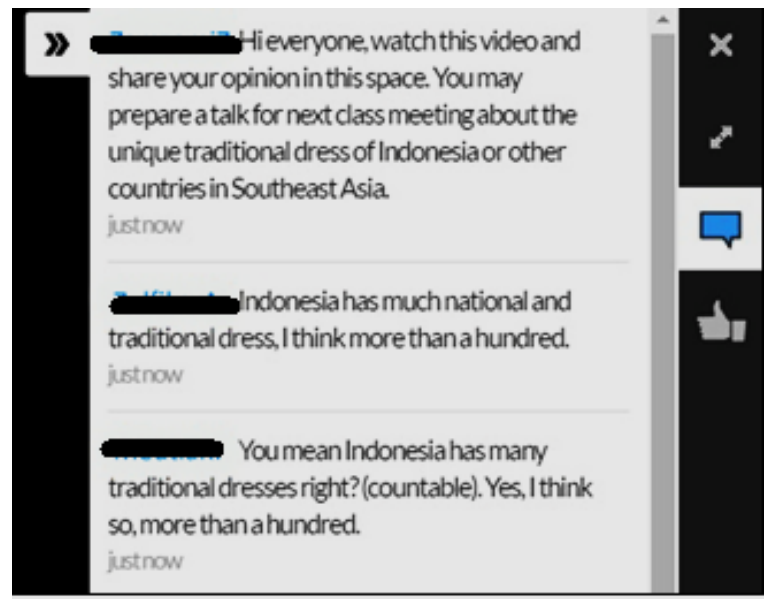

Figure 8. Student-peer evaluation on the LMS

Besides an online assessment, students were also able to evaluate themselves and their face-to-face meeting. Small group discussion in the class provided peer-feedback on their works. Even the instructor allocated a 15-minute interactive feedback session at the end of every class meeting. This session also enabled the instructor to evaluate the whole in-class activities, including the 40-minute listening exercise and 45minute conversation activities, as well as online activities on the LMS TES BlendSpace including watching a video lesson and online discussion. The students also verbalized that the instructor was able to deliver immediate feedback online outside of the class and offline in the class hours for their improvement. For in-class evaluation, the instructor gave some comments, clarifications, suggestion, and explanations about the topics they had discussed. Student G mentioned:

"When I posted a wrong comment on the Web, the instructor would correct immediately, he never says wrong to my answer, he always gives comment and suggestion for my improvement."

".......before finishing the class, the lecturer always asked students to give feedback about our class activities, and finally she evaluated our activities by giving some comments, clarifications, suggestion, and explanations about the topics." (Student C)

In the face-to-face class meeting, the instructor also concluded the class with an evaluation. The instructor gave some suggestions and corrections for students' mistakes during a group discussion.

\section{DISCUSSION AND RECOMMENDATIONS FOR FUTURE RESEARCH}

The rapid developments of technology and the use of LMS in teaching-learning a foreign language have transformed the conventional educational instruction into technology-based learning (Alharbi \& Drew, 2014). Nowadays, countless universities worldwide have utilized the LMS to enhance the quality of the teachinglearning process as it provides learners with technological abilities, supports learners to be more interactive and to save the time in transferring contents (Samarawickrema \& Stacey, 2007). All in all, this study has contributed to the literature by increasing the employment of flipped-class instruction to EFL studies. Flipped-class instruction is arguably one of the most promising methods in teaching the EFL classroom today (Chuang et al., 2018; Hung, 2015; Wu, Hsieh, \& Yang, 2017), with an integration of technology and pedagogy to promote positive learning outcomes.

This study confirms that the employment of LMS TES BlendSpace in the EFL flipped-class instruction has promoted students' self-directed learning skills and improved learning performance. It can be implied that by flipping the EFL class and employing a videorecorded lecture and LMS, particularly in the speaking class or general English course, it may save instructors' time in printing hard copy materials and provide more times for students-peers or students-instructor interaction. In addition, it will also assist students' preparation outside of class, engagement in activities, and subsequent discussions during class activities. Students come to class prepared and ready to engage the material. They are able to practice their English skills through a presentation, conversation, discussion, ask and answer the problem, or investigate possible solutions. In other words, this instruction can be thought 
of as a way of enhancing student preparedness, which in turn allows for more efficient use of in-class time. This finding is in line with a statement of Garrison (1997) that with a self-directed learning skill, the learners would be able to collaborate with peers, solve the problem independently, and work autonomously through intrinsic motivation and self- efficacy.

More comprehensively, in the interviews, overall students' perceptions were positive, particularly in terms of receiving and distributing information through the LMS outside of class time, as well as monitoring learning activities. The students were positive that they were able to review the pre-class learning content, particularly with regard to note-taking of any questions posed during their self-study outside of the class. They were able to pause, rewound and replayed the video lectures as they needed (Kurt, 2017). The LMS TES BlendSpace used in the study was designated in order for students to be able to monitor the progress of teaching-learning activities twenty-four hours a day. Students were able to read their peers' comments in other postings for comparison and self-evaluation in English. The LMS becomes a crucial device for college students to monitor and update all information related to teaching-learning activities and obtain instant notifications from their instructors (Orooji \& Taghiyareh, 2015). Another positive side reported that this type of instruction allocates more times for the students to interact and practice English with peers and instructors both in and out of class hours. It helped students to exchange knowledge with each other and helped low ability students to learn and ask questions to their peers. In line with this, Meskill and Anthony (2015) notify that the LMS allows students to form social connection and personality, particularly outside the class time for asynchronous mode of teaching and learning a foreign language. Moreover, in terms of selfevaluating learning skills, all interviewees acknowledged that the flipped class projects provided them with chances to evaluate their own performances as well as their peers. Besides, it also enabled them to know their peers' level in understanding the subject.

The findings of the interviews were in line with previous reports that the employment of pre-class online video course content before in-class activities might work best for language learners in fostering motivation, self-paced learning skills, knowledge-exchange, and information distribution (Chuang et al., 2018). Besides, students' metacognitive skills were also reported enhanced in the EFL flipped classroom implementation through self-control and self-regulation of learning, particularly during outside of class activities (Kim, Park, Jang, \& Nam, 2017). Another finding revealed a higher level of self-efficacy beliefs and better learning outcomes for the experimental group of a pre-service English teacher in the flipped classroom. Participants' perceptions were also positive, particularly with regard to note-taking of any questions posed during their selfstudy outside of the class. They were able to pause, rewound and replayed the video lectures as they needed
(Kurt, 2017). This report highlights the fact that EFL learners in flipped-class instruction can benefit from reviewing pre-class materials since having prior knowledge can improve their ability to engage during a class session. Promoting students' self-directed learning skills has been a longstanding goal in learning a foreign language, and there is a general agreement that it is not enough time for the students to engage in a conversation during class time due to schedule limitations. As such, there is a need for students to frequently practice the language outside of class (Davis, 2013).

Furthermore, in order to avoid a failure caused by flipping the class, future EFL instructors or researchers should seriously consider the activity and content provided on the LMS must be attractive in order to engage students' learning autonomously before class. The creative and innovative activities on the LMS as well as instructor involvement play a significant role to support students' participation. Nowadays, students often access various websites for various purposes, and they tend to give more attention to interesting websites. Therefore, there is an urgent need for instructors to utilize interesting materials available online for students' learning activities. This way, students would access the web regularly. Students' engagement on the web usually comes from its interesting contents. Interesting elements and activities on the LMS will motivate students to log in the LMS for learning activities outside the class hours.

Meanwhile, this study has a number of limitations that should be evaluated in future studies. The sample of the study was relatively small $(n=10)$. Those who were passive in-class activities tended to be silent or might not be confident enough to volunteer themselves in the interview sessions. Therefore, further study may include a bigger sample size. Differences in gender attitudes may also be one of the areas to be studied. Looking at the result of this study, we suggest that various LMSs should be implemented in teachinglearning EFL in Indonesian higher education. It will provide students the opportunity to improve their listening, writing, reading, vocabulary, as well as technical skills outside of the class hours. It would also prepare students to get ready for in-class activities. Finally, the implementation of flipped-class instruction in foreign language studies is highly recommended in order to reform the teaching practice from pursuing a conventional teacher-centered to a student-centered approach, with innovative instructions and twenty-firstcentury skills.

\section{CONCLUSION}

This study summarized some general advantages of the effectiveness of the LMS in teaching-learning English. The LMS TES BlendSpace has potentially contributed to the advancement of students' self-directed learning skills. The data collected in this study indicated that the use of the LMS in the EFL flipped classroom has influenced five learners' autonomy abilities, namely, 
receiving and distributing information, monitoring learning activities outside of class, students' pre-class learning content, peer interaction, and self-evaluating learning skills. By employing the LMS TES BlendSpace in the EFL class, the students were able to distribute and receive new information and continue online learning activities outside the class. Students were able to monitor learning activities, mastered the content before attending the class, and established online interaction with peers and instructors. It also allowed self-evaluation, peer-evaluation, and instructorevaluation with regard to the learning process. This study recommends EFL instructors to implement the TES BlendSpace and other LMSs to support students' self-directed learning skills.

\section{REFERENCES}

Alharbi, S., \& Drew, S. (2014). Using the technology acceptance model in understanding academics' behavioural intention to use learning management systems. International Journal of Advanced Computer Science and Applications, 5(1), 143155. doi: 10.14569/IJACSA.2014.050120

Benson, P. (2009). Making sense of autonomy in language learning. In S. Toogood, R. Pemberton \& A. Barfield (Eds.), Maintaining control: Autonomy and language learning (pp. 13-26). Hong Kong: Hong Kong University Press.

Bergmann, J., \& Sams, A. (2012). Before you flip, consider this. Phi Delta Kappan, 94(2), 25. doi: 10.1177/003172171209400206

Brookfield, S. D. (2009). Self-directed learning. In International handbook of education for the changing world of work (pp. 2615-2627). Springer, Dordrecht.

Creswell, J. W. (2012). Research design: Qualitative, quantitative, and mixed methods approaches. Los Angeles: Sage.

Chuang, H. H., Weng, C. Y., \& Chen, C. H. (2018). Which students benefit most from a flipped classroom approach to language learning?. British Journal of Educational Technology, 49(1), 56-68. doi: 10.1111/bjet.12530

Dabbagh, N., \& Kitsantas, A. (2013). Using learning management systems as metacognitive tools to support self-regulation in higher education contexts. In International handbook of metacognition and learning technologies (pp. 197211). Springer, New York, NY.

Davis, M. (2013). Beyond the classroom: The role of self-guided learning in second language listening and speaking practice. Studies in Self-Access Learning Journal, 4(2), 85-95.

Garrison, D. R. (1997). Self-Directed Learning: Toward a Comprehensive Model. Adult Education Quarterly, 48(1), 18-33. doi: 10.1177/074171369704800103

Hwang, G. J., Chiu, L. Y., \& Chen, C. H. (2015). A contextual game-based learning approach to improving students' inquiry-based learning performance in social studies courses. Computers \& Education, 81, 13-25.

Hung, H. T. (2015). Flipping the classroom for English language learners to foster active learning. Computer Assisted Language Learning, 28(1), 81-96. doi: 10.1080/09588221.2014.967701

Kim, J., Park, H., Jang, M., \& Nam, H. (2017). Exploring flipped classroom effects on second language learners' cognitive processing. Foreign Language Annals, 50(2), 260-284. doi: 10.1111/flan.12260

Kim, M. K., Kim, S. M., Khera, O., \& Getman, J. (2014). The experience of three flipped classrooms in an urban university: An exploration of design principles. The Internet and Higher Education, 22, 37-50. doi: 10.1016/j.iheduc.2014.04.003

Knowles, M. S. (1989). The making of an adult educator: An autobiographical journey. San Francisco, CA: Jossey-Bass.

Kurt, G. (2017). Implementing the flipped classroom in teacher education: evidence from Turkey. Journal of Educational Technology \& Society, 20(1), 211221.

Lai, C. (2015). Modeling teachers' influence on learners' self-directed use of technology for language learning outside the classroom. Computers \& Education, 82, 74-83. doi: 10.1016/j.compedu.2014.11.005

Lai, H., Hsiao, Y., \& Hsieh, P. (2018). The role of motivation, ability, and opportunity in university teachers' continuance use intention for flipped teaching. Computers \& Education, 124, 37-50. doi: 10.1016/j.compedu.2018.05.013

Lee, G., \& Wallace, A. (2018). Flipped learning in the English as a foreign language classroom: Outcomes and perceptions. TESOL Quarterly, 52(1), 62-84. doi: 10.1002/tesq.372

Lin, C. J., \& Hwang, G. J. (2018). A learning analytics approach to investigating factors affecting EFL students' oral performance in a flipped classroom. Journal of Educational Technology \& Society, 21(2), 205-219.

Lockwood, R. B., \& Folse, K. S. (2014). Flip It!: Strategies for the ESL Classroom. University of Michigan Press.

Long, H. B. (1989). Self-directed learning: Merging theory and practice. In H.B. Long (Eds.), Selfdirected learning: Merging theory and practice (pp. 1-12). Norman, OK: Research Center for Continuing Professional and Higher Education of the University of Oklahoma.

Meskill, C., \& Anthony, N. (2015). Teaching languages online (Vol. 12). Multilingual Matters.

$\mathrm{Ng}$, W. (2015). Technology integration and the flipped classroom. In New digital technology in education (pp. 149-169). Springer, Cham.

Orooji, F., \& Taghiyareh, F. (2015). Supporting participants in web-based collaborative learning 
activities from a holistic point of view: a tale of seven online and blended courses. Journal of Computers in Education, 2(2), 183-210. doi: 10.1007/s40692-015-0031-4

Samarawickrema, G., \& Stacey, E. (2007). Adopting web-based learning and teaching: A case study in higher education. Distance Education, 28(3), 313333. doi: 10.1080/01587910701611344

Slomanson, W. R. (2014). Blended learning: A flipped classroom experiment. Journal of Legal
Education, 64(1), 93-102.

Walder, A. M. (2015). Obstacles to innovation: The fear of jeopardising a professorial career. British Journal of Education, 3(6), 1-16.

Wu, W. C. V., Hsieh, J. S. C., \& Yang, J. C. (2017). Creating an online learning community in a flipped classroom to enhance EFL learners' oral proficiency. Journal of Educational Technology \& Society, 20(2), 142-157. 